\title{
ORIGINAL ARTICLE Genome-wide analysis of p53-regulated transcription in Myc-driven lymphomas
}

\author{
C Tonelli ${ }^{1}$, MJ Morelli ${ }^{2}$, A Sabò ${ }^{2}$, A Verrecchia $^{1}$, L Rotta ${ }^{1}$, T Capra $^{1}$, S Bianchi ${ }^{2}$, S Campaner $^{2}$ and B Amati $^{1,2}$
}

The tumour suppressor p53 is a transcription factor that controls cellular stress responses. Here, we dissected the transcriptional programmes triggered upon restoration of p53 in Myc-driven lymphomas, based on the integrated analysis of p53 genomic occupancy and gene regulation. p53 binding sites were identified at promoters and enhancers, both characterized by the preexistence of active chromatin marks. Only a small fraction of these sites showed the 20 base-pair p53 consensus motif, suggesting that p53 recruitment to genomic DNA was primarily mediated through protein-protein interactions in a chromatin context. p53 also targeted distal sites devoid of activation marks, at which binding was prevalently driven by sequence recognition. In all instances, the relevant motif was the canonical unsplit consensus element, with no clear evidence for p53 recruitment by split motifs. At promoters, p53 binding to the consensus motif was associated with gene induction, but not repression, indicating that the latter was most likely indirect. Altogether, our data highlight key features of genome recognition by p53 and provide unprecedented insight into the pathways associated with p53 reactivation and tumour regression, paving the way for their therapeutic application.

Oncogene (2017) 36, 2921-2929; doi:10.1038/onc.2016.443; published online 16 January 2017

\section{INTRODUCTION}

The tumour suppressor p53 acts as a stress sensor in response to stimuli such as hypoxia, DNA damage, oncogene activation and others. Once activated, p53 binds DNA and regulates complex gene expression programmes that contribute to cellular responses such as apoptosis, senescence or cell cycle arrest, preventing the dissemination of damaged cells. ${ }^{1,2}$ These processes are involved in tumour suppression, setting the selective pressure for $\mathrm{p} 53$ inactivation in tumours.

Using transgenic mice with conditionally active Trp53 alleles, four groups showed that reinstatement of p53 induces tumour regression, $^{3-6}$ pointing to the therapeutic potential of p53 restoration. In order to gain more insight into p53-regulated programmes that may contribute to therapy, we generated whole genome profiles of p53 binding and gene expression following p53 reactivation in Myc-driven lymphomas. Our data highlight basic principles underlying genome recognition by $\mathrm{p} 53$ and provide a unique resource for the identification of new p53regulated mediators of tumour suppression.

\section{RESULTS AND DISCUSSION}

Profiling the transcriptional response to p53 restoration in Myc-driven lymphomas

To comprehensively map p53-dependent responses in Myc-driven lymphomas, we compared the expression changes triggered by different modes of p53 restoration. As p53 induces apoptosis in those tumours, ${ }^{3,7,8}$ we selected early time-points in order to profile transcriptional responses in the absence of excessive cell death.

As a first model, we used tumours arising in E $\mu$-myc mice heterozygous for a knock-in allele $\left(\operatorname{Trp} 53^{K l}\right)$ that expresses the conditional p53ER ${ }^{\text {TAM }}$ fusion protein. ${ }^{3,9}$ Prior to p53ER ${ }^{\text {TAM }}$ activation by 4 -hydroxytamoxifen (OHT), $\operatorname{Trp} 53^{K l}$ shows minimal p53 activity: ${ }^{10}$ hence, as previously observed in E $\mu$-myc Trp53 $3^{+/-}$ mice, ${ }^{11,12}$ E $\mu$-myc Trp53 $3^{K I /+}$ animals develop aggressive lymphomas that have inactivated the remaining wild-type allele. ${ }^{3}$ The resulting $\mathrm{E} \mu$-myc $\operatorname{Trp} 53^{K / / \Delta}$ lymphomas were established in culture to address the effects of $\mathrm{p} 53$ restoration through the activation of ${\mathrm{p} 53 E \mathrm{R}^{\mathrm{TAM}}}^{\text {. As expected, }}{ }^{3}$ OHT treatment rapidly induced cell death, most of the cultures showing an almost complete loss of viability within $10 \mathrm{~h}$ (Supplementary Figure S1a). Representative p53 target genes were induced already at $2 \mathrm{~h}$ (Supplementary Figure S1b), preceding cell death: we thus profiled gene expression at this time-point.

As a second model, we used E $\mu$-myc lymphomas that had lost

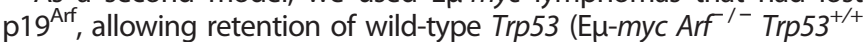
lymphomas): ${ }^{11,12}$ these were treated in vitro with either doxorubicin (adriamycin), a DNA damaging agent commonly used to activate p53, ${ }^{13}$ or Nutlin, a non-genotoxic molecule that interferes with the ability of Mdm2 to target p53 for degradation. ${ }^{14}$ Nutlin is a chiral molecule, the active enantiomer (-)-Nutlin (hereafter 'Nutlin') binding Mdm2 150 times more potently than (+) - Nutlin: ${ }^{14}$ we thus used the latter as a control for off-target effects. As above, a timecourse experiment was performed to determine the best time-point for RNA profiling: at $3 \mathrm{~h}$ of treatment, we could detect clear accumulation of the p53 protein and induction of p53 target genes, preceding either apoptosis or alterations in cell cycle profile (Supplementary Figures S2a-d).

The above conditions were used to profile gene expression with RNA-Seq technology. Differentially expressed genes (DEGs) were called in each treated sample relative to the corresponding control, revealing variable numbers and proportions of up- and down-regulated mRNAs (DEG up, DEG down; Figure 1a, Supplementary Tables S1-S3). The genes that responded to p53ER ${ }^{\text {TAM }}$ restoration and to Nutlin treatment represented a subset of the doxorubicin-responsive ones (Figure 1a). Moreover,

\footnotetext{
${ }^{1}$ Department of Experimental Oncology, European Institute of Oncology (IEO), Milan, Italy and ${ }^{2}$ Center for Genomic Science of IIT@SEMM, Fondazione Istituto Italiano di Tecnologia (IIT), Milan, Italy. Correspondence: Dr B Amati, Department of Experimental Oncology, European Institute of Oncology (IEO), Via Adamello 16, 20139 Milan, Italy. E-mail: bruno.amati@ieo.it

Received 4 May 2016; revised 16 September 2016; accepted 14 October 2016; published online 16 January 2017
} 
a

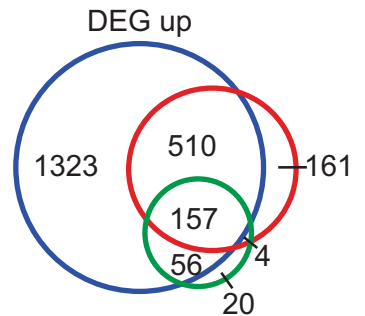

b
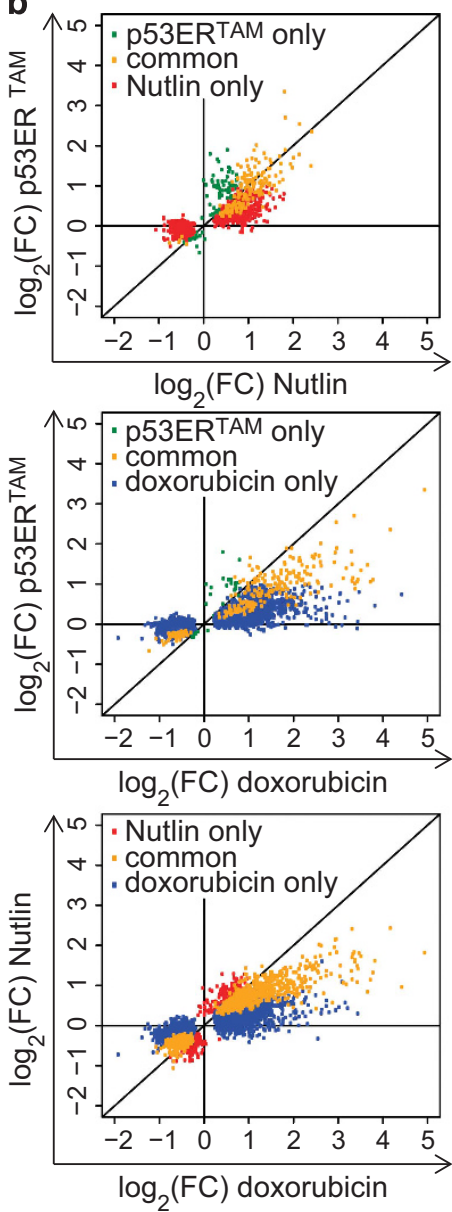
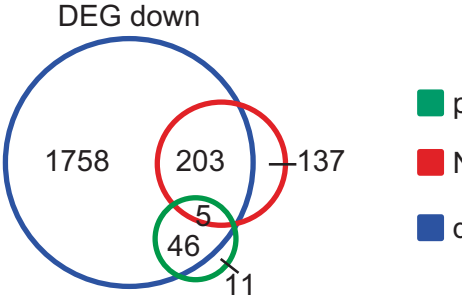

DEG up

DEG down

C

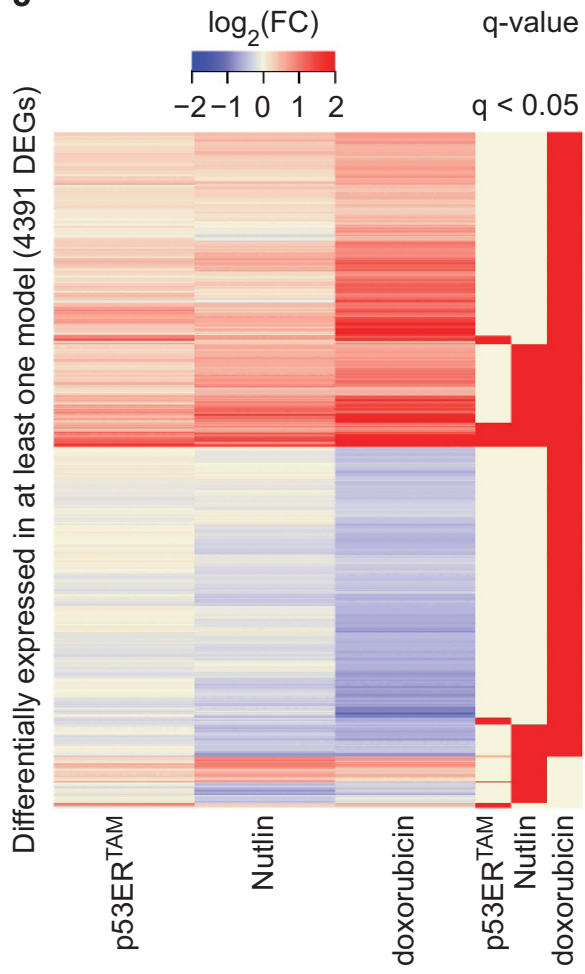

d

p53-dependent DEGs

p53-independent DEGs

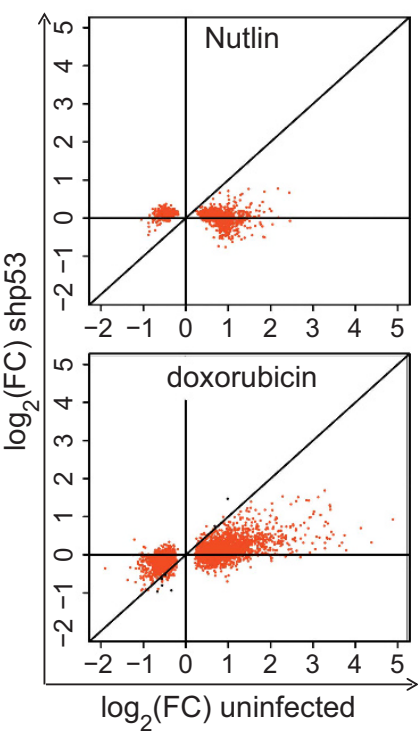

Figure 1. Expression profiling during E $\mu$-myc tumour regression. (a) Overlap between the DEGs identified by RNA-Seq following p53 restoration in the indicated models. Induced and repressed genes (DEG up, DEG down) were called based on the consistency of RNA changes in the treated samples relative to the controls. The percentages of up- and down-regulated genes are indicated relative to total DEG number. (b) Comparison of fold-change values $\left(\log _{2}(F C)\right)$ of all DEGs called in the various models, as indicated. (c) Heatmap of the log $2(F C)$ values and q-values of all up- and down-regulated genes $(n=4391)$ upon p53 restoration in the various models. The genes are clustered hierarchically on the basis of their differential expression and the statistical significance. (d) Effect of p53 knockdown (shp53) on the response to Nutlin or doxorubicin in E $\mu-m y c \mathrm{Arf}^{-1-} \operatorname{Trp} 53^{+/+}$lymphomas.

the majority of the genes induced upon p53ER ${ }^{\text {TAM }}$ activation (161 genes, or $68 \%$ ) also responded to Nutlin, while p53ER ${ }^{\text {TAM }}$ repressed genes showed a lower overlap (5 genes, or $8 \%$ ). The transcriptional changes induced by $\mathrm{p} 53 \mathrm{ER}^{\mathrm{TAM}}$ restoration were milder compared to the ones induced by either drug, with doxorubicin inducing the strongest changes (Figure 1b), most likely reflecting higher p53 levels (Supplementary Figure S2a). Despite these differences in magnitude and in the numbers of RNAs called as DEGs, we observed consistent expression changes across models (Figures $1 \mathrm{~b}$ and c). Hence, p53-dependent responses were generally similar, but a fraction of the responsive genes failed to score as differentially expressed in the weaker treatments since they did not reach the threshold of statistical significance. In all instances, the magnitude of gene activation was larger than that of repression (Figures $1 \mathrm{~b}$ and $\mathrm{c}$ ).

To assess the p53 dependency of the observed gene expression changes, we infected E $\mu$-myc $\mathrm{Arf}^{-1-} \mathrm{Trp53^{+/+ }}$ lymphomas with a retroviral vector expressing a Trp53-specific shRNA. This effectively knocked down Trp53 (Supplementary Figure S3a) and eliminated the expression changes induced by Nutlin (Figure 1d, top). Albeit still detectable, the responses to doxorubicin were generally suppressed (Figure 1d, bottom), with only 7 of the 4058 DEGs called in the control $(0.2 \%)$ still passing the statistical threshold. Since doxorubicin induced the strongest p53 activation (Supplementary Figure S2a), residual p53 in the presence of the Trp53 shRNA (Supplementary Figure S3b) may account for the 
a

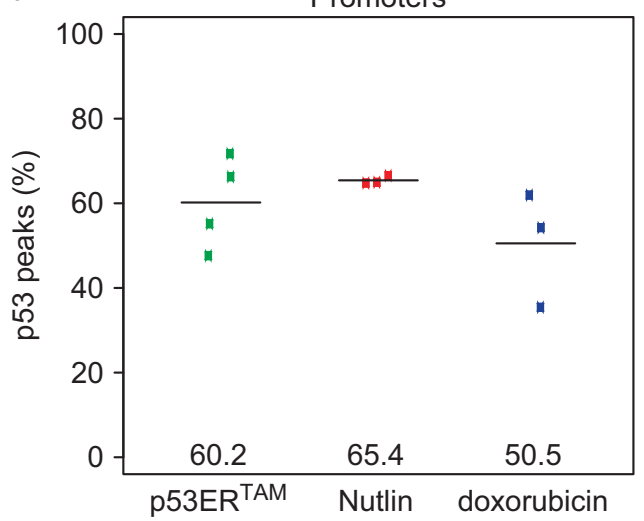

b

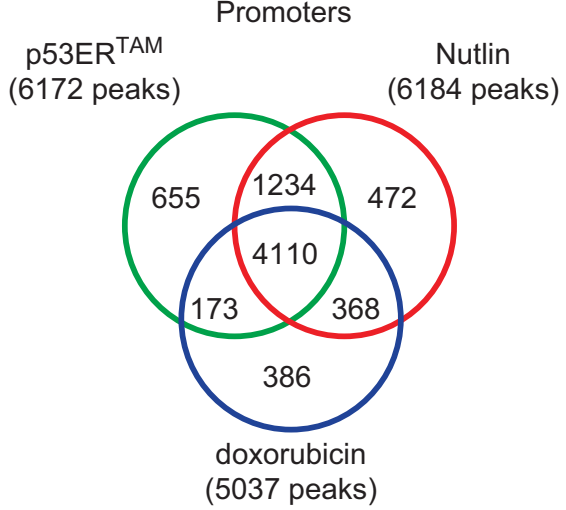

Distal sites

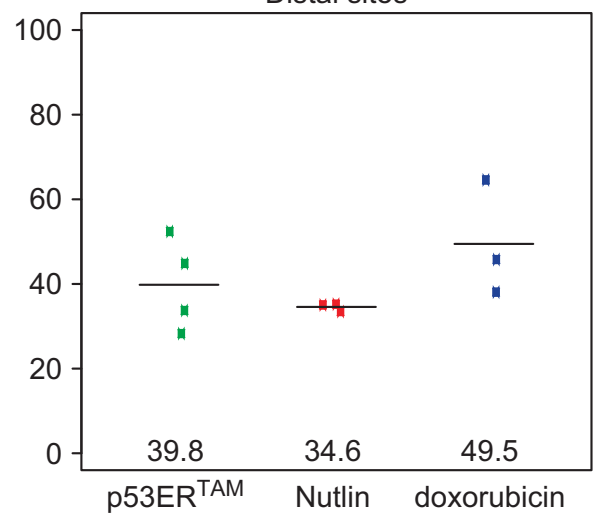

Distal sites

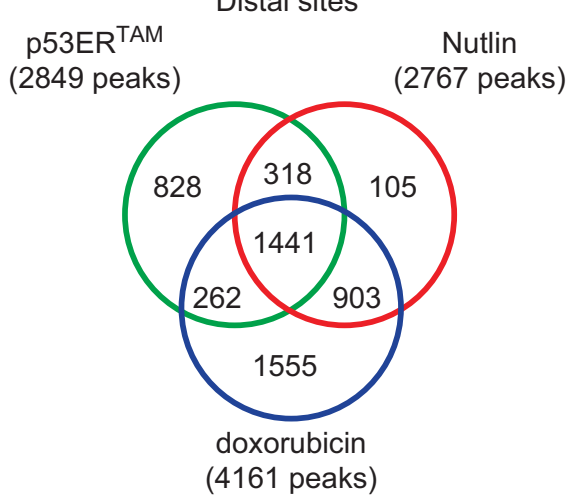

Figure 2. Genome-wide analysis of p53 binding sites. (a) Percentage of p53 peaks at promoters and distal sites in lymphomas following the indicated modes of p53 activation. (b) Venn diagram of p53 high-confidence binding sites at promoters and distal sites in each experimental model.

residual transcriptional responses. Thus, the gene expression changes induced by either treatment were globally p53dependent.

It is noteworthy here that different tumour-suppressive arms were engaged in the different models: the p19 ${ }^{\text {Arf }}$ axis was retained in E $\mu$-myc Trp53 ${ }^{K / / \Delta}$ lymphomas ${ }^{3}$ but not in E $\mu$-myc Arf $^{-/-}$Trp $53^{+/+}$ lymphomas, which retained the DNA damage response ${ }^{15}$ and the ribosomal stress pathways. ${ }^{16}$ Yet, the p53 signatures were very similar between the different models, suggesting that the cellular context — including here Myc-induced oncogenic stress — was more important than the p53-activating pathway in determining the $\mathrm{p} 53$ response.

Profiling of the p53 cistrome in Myc-driven lymphomas

The genomic occupancy of p53 was profiled with ChIP-Seq technology at the same time-points used for RNA-Seq. In all models, p53-DNA interactions were already detectable in vehicle-treated cells and strongly increased upon p53 restoration, in number and binding intensity (Supplementary Figures S4a-e). The solvent used to solubilize Nutlin (DMSO) was previously deemed to induce p53 binding to many sites. ${ }^{17}$ In our hands, however, various control treatments (including $\mathrm{H}_{2} \mathrm{O}$, DMSO and $(+)-$ Nutlin) yielded equivalent $\mathrm{p} 53$ binding profiles, neither showing activation of p53 relative to untreated cells (Supplementary Figures S5a and b). Most importantly, the specificity of the anti-p53 antibody used in our experiments was demonstrated by ChIP-Seq analysis in splenic cells from irradiated $\operatorname{Trp53^{-/-}}$ mice. ${ }^{18}$ Hence, in all the models used here, re-instatement of p53 in lymphomas led to its association with thousands of genomic sites.

The majority of the p53 binding sites were promoter-proximal, occurring between -5 and $+2 \mathrm{~kb}$ from an annotated transcription start site (TSS) (Figure 2a). Within each experimental model, treated samples showed consistent overlaps of the p53 peaks called at either promoters or distal sites, the samples with fewer peaks being entirely contained within those with larger peak numbers (Supplementary Figures S6a and c), and the strongest binding events enriching for peaks shared among samples (Supplementary Figures S6b and d). For all subsequent analyses, we defined high-confidence p53 binding sites as peaks that were identified in at least two lymphomas for each treatment: at promoters, the majority of these sites were common to all modes of p53 activation (Figure 2b, left). Distal binding sites also showed a good level of overlap, although higher numbers of nonoverlapping peaks were observed with p53ER ${ }^{\text {TAM }}$ activation or doxorubicin treatment (Figure 2b, right).

To understand the basis of DNA recognition at promoterproximal sites, we analysed the occurrence of the p53 consensus motif (p53-response element, or p53-RE; Jaspar database), ${ }^{19}$ accounting also for split variants with a spacer of 1-15 nucleotides between the two decameric half sites. ${ }^{20} 4-9 \%$ of the p53-bound promoters contained an unsplit p53-RE, while $27-30 \%$ included a split motif. Yet, only the unsplit motif was significantly enriched relative to the random expectation (Figure 3a). Thus, in agreement with a previous report, ${ }^{21}$ our data did not provide any evidence for p53 recruitment to be mediated by the split motif with a variable spacer sequence. Analysis of the positions of p53 peaks and of the motifs in promoters reinforced this point: in the presence of an unsplit motif, p53 binding occurred at variable distance from the TSS; instead, at promoters with either a split or no motif, virtually all of the binding sites occurred within $500 \mathrm{bp}$ from the TSS (Supplementary Figure S7a). In line with this observation, p53 peaks containing the unsplit motif were distributed over larger distances from RNA polymerase II (RNA pollI), while those with a 
a

$$
\begin{aligned}
& \square \text { No motif } \\
& \square \text { Split (1-15 spacer) } \\
& \square \text { Unsplit (no spacer) }
\end{aligned}
$$

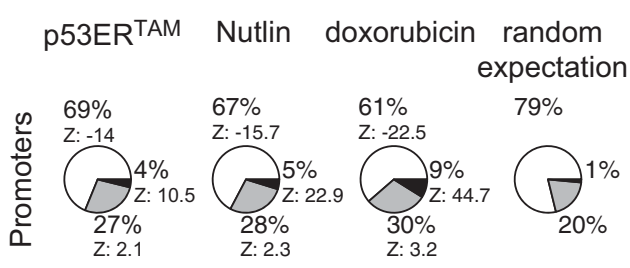

d

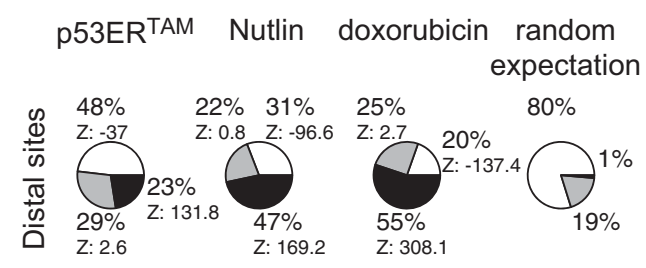

b
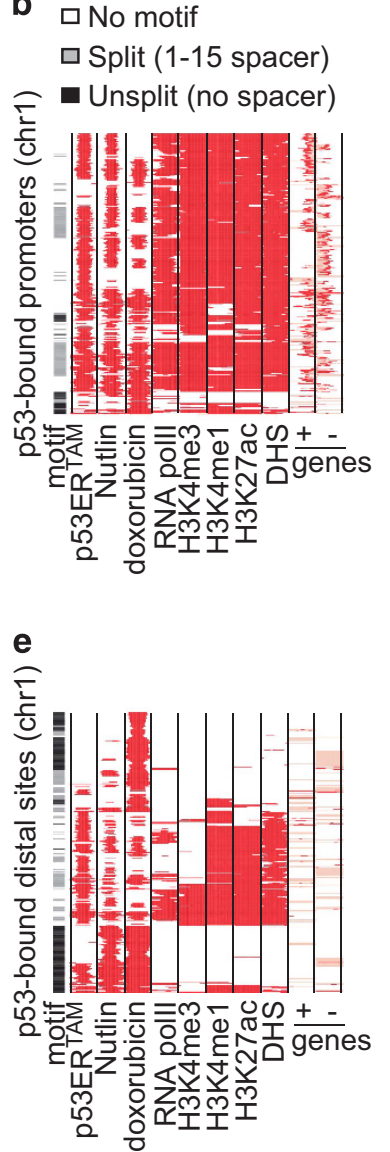

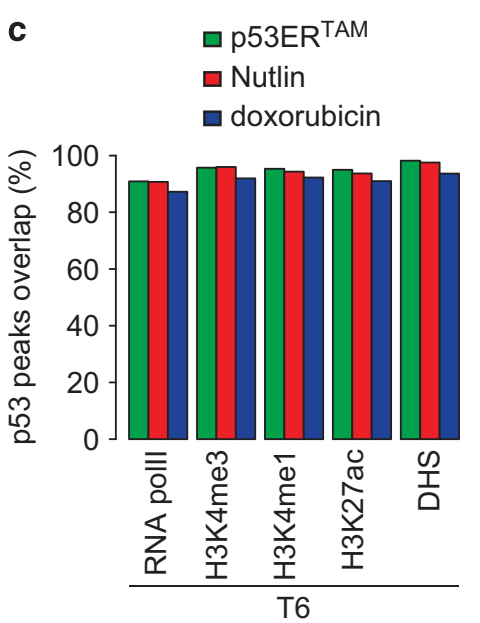

f

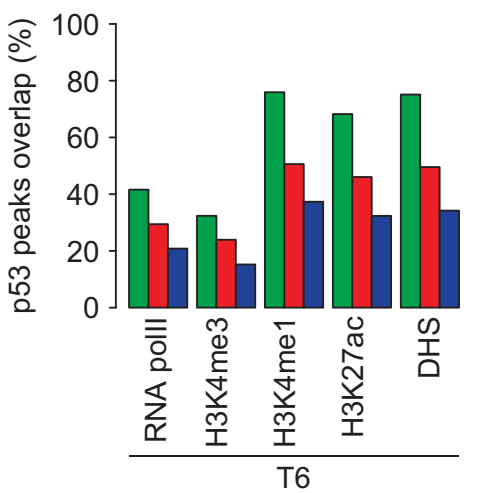

Figure 3. Characterization of p53 binding sites. (a, d) Percentage of p53 peaks containing no motif, a motif with a 1-15 nt spacer, or with no spacer at promoters (a) and distal sites (d) following the indicated modes of p53 activation. Z: significance of the enrichment (see Material and methods). (b, e) Distribution of high-confidence p53 peaks at promoters (b) and distal sites (e) across the different models. Rows represent different sites, with each column reporting a $1 \mathrm{~kb}$ genomic interval centred on the p53 peak. The panels include every region of chromosome 1 that was identified as p53-associated by ChIP-Seq in at least one of the experimental samples. The occurrence of the p53-RE at the genomic intervals analysed is indicated, on the left side of the heatmap, with black lines for the unsplit motif and grey lines for the split motif. For the same intervals, the distribution of RNA polll, H3K4me3, H3K4me1, H3K27ac, DHS mapped in vivo in untreated lymphoma T6 ('T1' in Sabò et al. $^{22}$ ) and annotated genes (exons in red, introns in pink; +sense, - antisense strand) are also shown. (c, f) Percentage of high-confidence p53 peaks at promoters (c) and distal sites (f) following the indicated treatments that overlap with pre-existing features (RNA polll, H3K4me3, H3K4me1, H3K27ac, DHS).

split motif or no motif more frequently overlapped with RNA polll (Supplementary Figures S7b and c). Furthermore, compared with the split motif, the unsplit p53-RE showed better co-localization with the midpoint of the p53 peak (Supplementary Figure S7d). Altogether these data suggested that p53 binding to the unsplit motif was driven by sequence recognition, while its binding to DNA regions with the split or no recognizable motif was largely dependent on its interactions with the transcriptional machinery. To address this further, we overlapped our p53 profiles at promoters with previously profiled features in untreated lymphoma cells, ${ }^{22}$ including RNA polll, the active histone marks H3K4me3, H3K4me1 and H3K27ac, as well as DNasel hypersensitive sites (DHS) (Figures $3 \mathrm{~b}$ and c). Virtually all p53-bound promoters shared these features, indicating that p53 associated with active promoters that were pre-loaded with RNA polll. Altogether, these data indicate that we are distinguishing two types of p53-bound promoters: those with a canonical unsplit p53-RE, at which p53 recruitment was directed by sequence recognition, and all others, at which $\mathrm{p} 53$ localization was most likely constrained by the transcriptional machinery and/or chromatin-associated features, with no evident contribution of direct sequence recognition.
The above analyses were repeated for distal peaks: first, these binding sites altogether showed markedly increased proportions of peaks with the unsplit p53-RE, ranging from 23 to $55 \%$, significantly over random expectation (Figure 3d). Remarkably, these unsplit p53-RE-containing sites mainly occurred in chromatin domains devoid of the investigated active marks and resistant to DNasel prior to p53 activation (Figure 3e). These unmarked distal sites were recently proposed to act as a 'proto-enhancers',23 and to be included in repeated elements of viral origin; ${ }^{24}$ however, their functional nature remains still unclear and requires further investigation. The rest of the p53-bound distal sites co-localized with H3K4me1, H3K27ac, as well DHS domains, characteristic of active enhancers (Figures $3 e$ and f). Of note, the majority of these p53-bound enhancers contained either the split p53-RE or no recognizable motif (Figure 3e). Altogether, these data suggest that DNA sequence recognition is the main determinant of p53 binding at distal heterochromatic regions, while other features relax this requirement at active enhancers. As for promoters, these features may include overall chromatin accessibility and active recruitment via protein-protein interactions. Most importantly, whether at promoters, enhancers or unmarked distal sites, peaks with the unsplit motif showed on average the highest binding 
a

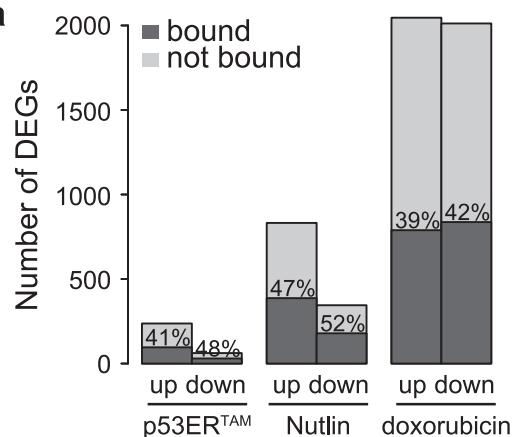

b

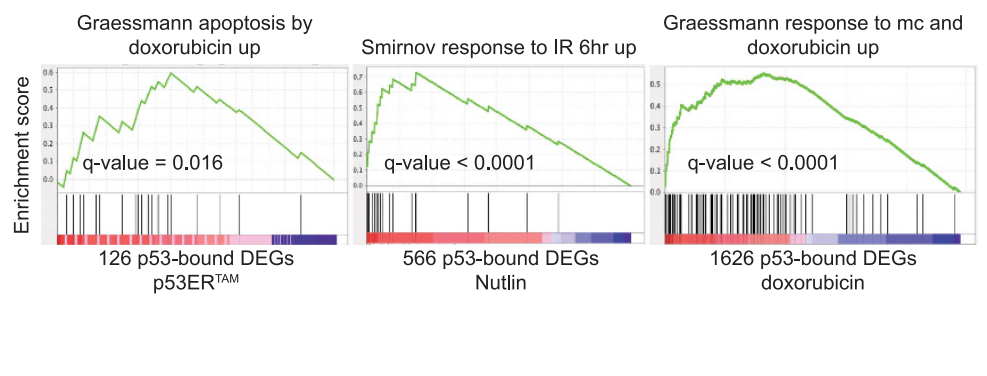

C

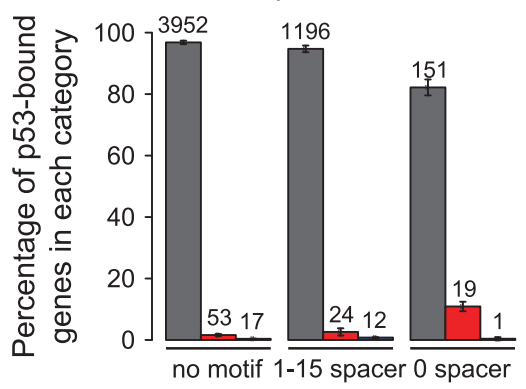

d

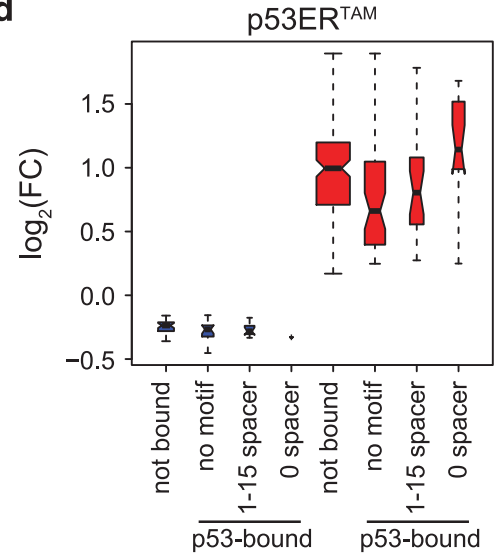

Nutlin

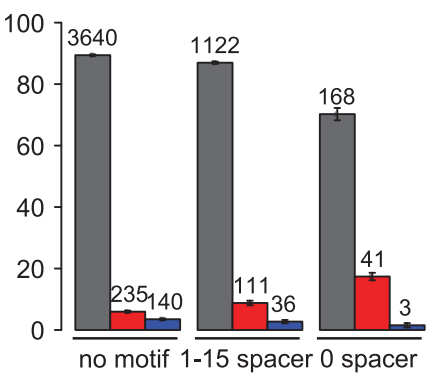

Nutlin

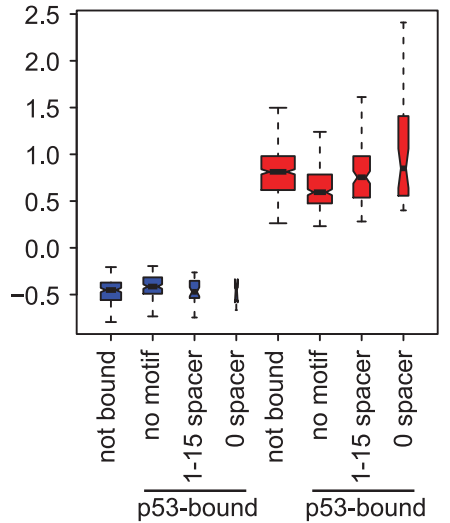

doxorubicin

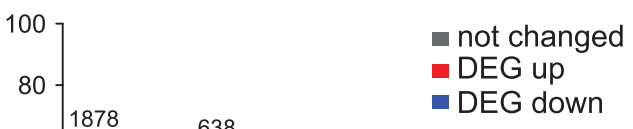

- DEG up
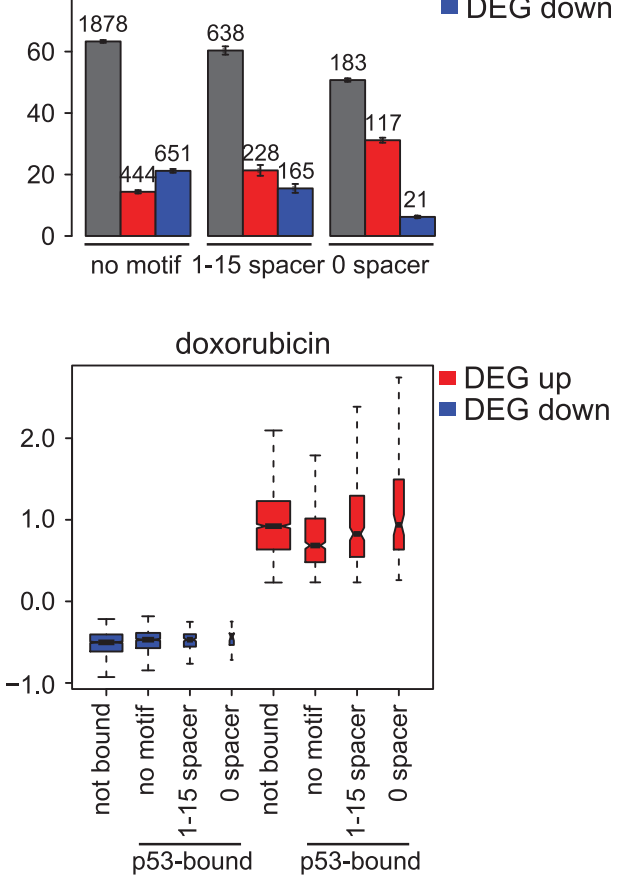

Figure 4. Analysis of p53-bound and-regulated genes during E $\mu$-myc tumour regression. (a) Absolute numbers and percentages of DEGs with a high-confidence p53 binding site in the promoter-proximal region in the indicated models. (b) Top gene sets from GSEA on the p53-bound and -regulated genes in the different models. (c) Percentages and absolute numbers of p53-bound genes (with either no motif, a motif with a

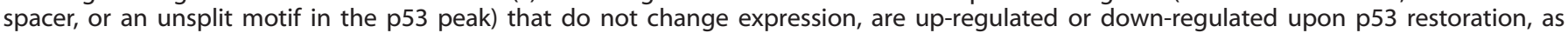

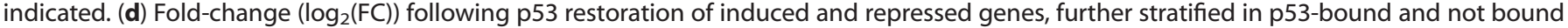
and containing or not the indicated motifs.

intensities (Supplementary Figure S7e). The p53 binding sites without motif presented on average the lowest enrichment levels: the high degree of overlap observed among samples (Supplementary Figure S6) together with the low binding intensity (Supplementary Figure S7e) indicate that these p53 binding sites represent true low-affinity interactions, which were captured by formaldehyde cross-linking, are not necessarily functional (see below), and are most likely due to scanning of open chromatin by the $\mathrm{p} 53$ protein, as proposed for other transcription factors (for example Myc). ${ }^{22}$ We validated some of the enhancers and unmarked distal sites with the unsplit motif by ChIP-qPCR (Supplementary Figure S8).

Finally, to address the level of conservation of p53 binding sites in other contexts, we compared our p53 binding patterns with published ChIP-Seq studies. Virtually all p53 binding sites identified here in lymphomas were present in normal mouse $B$ cells after in vivo irradiation ${ }^{18}$ (Supplementary Figure S9a). Hence, given the same cellular context, p53 bound a common set of sites irrespective of the type of stimulus. From 10 to $25 \%$ of the promoter peaks and 20 to $70 \%$ of the distal peaks were also present in doxorubicin-treated mouse embryonic stem cells $(\mathrm{mESC})^{25}$ and fibroblasts (MEF), ${ }^{26}$ respectively (Supplementary Figures S9b and c). Of note, the overlaps further increased when restricting the analysis to peaks containing the unsplit p53-RE, indicating that these are most frequently maintained between different cell types (Supplementary Figures S9a-c). These observations support the existence of a 'default set' of p53 binding sites that is not influenced by the activating stimulus or the cellular context, as previously proposed. ${ }^{27-29}$ It is noteworthy here that the majority of the distal p53 binding sites containing the canonical unsplit motif (characteristic of the unmarked distal sites) were independently identified in doxorubicin-treated mESCs and MEFs with $>90 \%$ and $66-72 \%$ overlap, respectively (Supplementary Figures S9b and c). 
Correlating p53 binding events with transcriptional regulation

To identify which of the genes regulated upon p53 restoration in lymphomas were direct p53 targets, we combined p53 binding and expression profiles. In all instances, approximately half of the up- and down-regulated genes presented a high-confidence p53 peak in the promoter-proximal region (Figure 4a, Supplementary Tables S4-S6). A Gene Set Enrichment Analysis (GSEA) of the p53bound and -regulated genes in the different models revealed signatures connected with p53 biology (Figure 4b, Supplementary Tables S7-S9). ${ }^{30,31}$

In line with previous reports, ${ }^{17,18,26,28}$ promoter binding per se was not predictive of transcriptional regulation since the majority of the p53-bound genes did not change expression following p53 activation (Figure 4c). However, (i) the percentage of up-regulated genes was higher when considering p53-bound promoters with an unsplit p53-RE (Figure 4c), (ii) the presence of the motif correlated with larger amplitudes in gene activation (Figure 4d) and (iii) among the p53 peaks with the motif, those at p53activated promoters showed on average the highest enrichment levels, suggesting a positive correlation between binding intensity and transcriptional output (Supplementary Figure S10). Remarkably, the opposite was true for down-regulated genes, which were under-represented among promoters with the unsplit p53-RE. Thus, albeit not an absolute determinant, binding of p53 to an unsplit motif preferentially associated with activation of the corresponding promoter. Of note, the overlap of the up-regulated DEGs in the different models increased for the targets bound by p53 at the unsplit motif (Supplementary Figure S11a). A biological process Gene Ontology and KEGG pathway analysis on the upregulated genes in the different models indicated that the p53bound genes not containing the motif enriched for terms related to transcription and chromatin organization, while the targets containing the unsplit p53-RE were associated with p53 signalling pathway, apoptosis, negative regulation of cell growth and DNA damage response (Supplementary Figure S11b). It is noteworthy here that some of the genes bound by p53 at the split motif were also involved in cell cycle and regulation of apoptosis. Included in this category are some well-known p53 targets such as Foxo3, ${ }^{32}$ Notch $1^{33}$ and Trp53inp 1. ${ }^{34}$ Although our data do not provide any evidence for $\mathrm{p} 53$ recruitment to be mediated by split motifs when 1-15 nt spacers are considered all together, they do not exclude that direct regulation of selected genes may occur through a subset of split motifs or alternative binding sites.

Comparison of the p53-bound and -regulated genes identified in this study with recent investigations of the p53 transcriptional programme highlighted a group of well-known p53 target genes such as Cdkn1a, Mdm2, Btg2, Bax, Rps27l, Gadd45a, Sesn2 and many others, which were activated in most studies (Supplementary Figure S12, Supplementary Table S10). On top of this core response, each model induced an additional programme, which was instead context- or stimulus-specific. Several targets were validated by ChIPqPCR and expression analysis (Supplementary Figure S13). Altogether, our study provides a key resource for the investigation of the p53 programme in tumour regression.

\section{MATERIALS AND METHODS}

Mouse breeding and genotyping

The following mouse strains were used for this study: $\mathrm{E} \mu-\mathrm{myc}^{35}$ and $\mathrm{Arf}^{+/-}$ animals $^{36}$ (C57/Bl6 background), as well as Trp53 ${ }^{K 1}$ mice ${ }^{9}$ (mixed background). Animals were bred to obtain the various genotype combinations described in this paper. Primers used for genotyping were GGTTAA

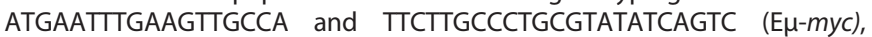
CCTCCAGCCTAGAGCCTTCCAAGC, GGTGAGATTCATTGTAGGTGCC and GCACACAAACTCTTCACCCTGC $\left(\operatorname{Trp} 53^{K l}\right)$, and AGTACAGCAGCGGGAGCA TGG, TTGAGGAGGACCGTGAAGCCG and ACCACACTGCTCGACATTGGG $\left(\operatorname{Arf}^{+/-}\right)$.
Experiments involving animals were performed in accordance with the Italian Laws (D.lgs. 26/2014), which enforces Dir. 2010/63/EU (Directive 2010/63/EU of the European Parliament and of the Council of 22 September 2010 on the protection of animals used for scientific purposes).

\section{Primary mouse B-cell lymphomas}

Four $\mathrm{E} \mu$-myc $\operatorname{Trp} 53^{K / / \Delta}$ lymphomas arising in $\mathrm{E} \mu-m y c$ mice heterozygous for a knock-in allele $\left(\operatorname{Trp} 53^{K l}\right)$ that expresses the conditional p53ER ${ }^{\text {TAM }}$ fusion protein were used in this study: T1 was kindly provided by $\mathrm{Dr}$ G. Evan, while T2, T3 and T4 were generated in-house. Three E $\mu-m y c$ Arf $^{-/}-T_{r p 5} 3^{+/+}$ lymphomas were employed in this study: T5 arose in an E $\mu-m y c \mathrm{Arf}^{+-}$ Trp $53^{+/+}$mouse and underwent loss-of-heterozygosity, while T6 and T7 arose in $\mathrm{E} \mu-m y c$ mice and p19 loss was verified by Western blotting. Lymphoma samples (or tumours, T) composed primarily of tumour cells, were dissected from infiltrated lymph nodes and not purified further. Cells were grown in 1:1 ratio of irradiated $\mathrm{NIH}-3 \mathrm{~T} 3$ conditioned medium and fresh medium (DMEM and IMDM (1:1), 10\% fetal bovine serum, $2 \mathrm{~mm} \mathrm{L-GIn,} 1 \%$ penicillin/streptomycin, $1 \%$ non-essential amino acids and $0.2 \% \beta$-mercaptoethanol).

Retroviral-mediated gene transfer was performed using Phoenix packaging cells. E $\mu$-myc $\mathrm{Arf}^{/-} \mathrm{Trp}^{2} 3^{+/+}$lymphomas cells were infected with the recombinant retrovirus PLEPG shp53.1224.

\section{Chemicals}

Doxorubicin hydrochloride (Sigma, St Louis, MO, USA) was used at a final concentration of $1 \mathrm{~mm}(0.6 \mathrm{mg} / \mathrm{ml}),(+)-$ and $(-)-$ Nutlin (Cayman Chemical, Ann Arbor, MI, USA) at $10 \mathrm{~mm}$ and OHT (Sigma) at $0.1 \mathrm{~mm}$.

\section{Western blotting}

$5 \times 10^{6}$ to $10 \times 10^{6}$ cells were lysed with RIPA Buffer $(50 \mathrm{~mm}$ Tris- $\mathrm{HCl} \mathrm{pH} \mathrm{8,}$ $150 \mathrm{~mm} \mathrm{NaCl}, 5 \mathrm{~mm}$ EDTA, $0.5 \% \mathrm{NP}-40,0.1 \%$ SDS) supplemented with protease inhibitors (Mini, Roche, Basel, CH, USA) and phosphatase inhibitors $(0.2 \mathrm{~mm}$ Ortovanadate, $5 \mathrm{~mm} \mathrm{NaF})$ and sonicated. Cleared lysates were electrophoresed and immunoblotted with primary antibodies against p53 (NCL-p53-CM5p, Novocastra laboratories, Newcastle upon Tyne, UK) or Vinculin (V9264, Sigma). After incubation with appropriate secondary antibodies, imaging was performed with either the LiCor Odyssey System for infrared acquisition or an enhanced chemiluminescence (ECL) detection kit (Bio-Rad, Hercules, CA, USA), followed by analysis with ChemiDoc XRS+ imaging system and Image Lab software (Bio-Rad).

\section{Flow cytometry: cell cycle and apoptosis analysis}

To analyse cell cycle and apoptosis, $1 \times 10^{6}$ live cells were resuspended in $1 \mathrm{ml}$ of PBS and fixed by adding $2 \mathrm{ml}$ of ice-cold absolute ethanol and kept at $4{ }^{\circ} \mathrm{C}$ for at least $30 \mathrm{~min}$. Cells were washed once with $1 \mathrm{ml}$ of PBS $1 \%$ BSA and stained overnight with $1 \mathrm{ml} 50 \mu \mathrm{g} / \mathrm{ml}$ propidium iodide and $250 \mu \mathrm{g} / \mathrm{ml}$ RNaseA at $4{ }^{\circ} \mathrm{C}$. At least 10000 total events were analysed by FACS. All the FACS data were acquired using a FACSCalibur machine (Becton Dickinson, Franklin Lakes, NJ, USA) and then analysed by using FlowJo software (TreeStar).

\section{Chromatin Immunoprecipitation}

Cells were processed as described above. Due to the clonal nature of lymphomas, we kept tumour samples separated and analysed four $\mathrm{E} \mu-m y c$ $\operatorname{Trp5} 3^{K / / \Delta}$ lymphomas treated with $100 \mathrm{~nm}$ OHT or $1 / 1000$ vol. ethanol for $2 \mathrm{~h}$ and three $\mathrm{E} \mu-m y c \mathrm{Arf}^{\prime-} \mathrm{Trp}^{2} 3^{+/+}$lymphomas treated with $5 \mu \mathrm{m}$ $(-)-$ Nutlin or $1 \mu \mathrm{m}$ doxorubicin for $3 \mathrm{~h}$ and the corresponding controls $\left(5 \mu \mathrm{m}(+)-\right.$ Nutlin or $1 / 1000$ vol. $\mathrm{H}_{2} \mathrm{O}$, respectively). For ChIP-Seq analysis of p53, lysates from $50 \times 10^{6} B$ cells were immunoprecipitated with $10 \mu \mathrm{g} \mathrm{p53}$ antibody (NCL-p53-CM5p - Novocastra laboratories). Cells were fixed by addition of $1 \%$ formaldehyde for $10 \mathrm{~min}$. Fixation was stopped by addition of $0.125 \mathrm{~m}$ glycine. Cells were washed three times in PBS, resuspended in SDS buffer $(50 \mathrm{~mm}$ Tris- $\mathrm{HCl}$ pH 8, 0.5\% SDS, $100 \mathrm{~mm} \mathrm{NaCl}, 5 \mathrm{~mm}$ EDTA, protease and phosphatase inhibitors) and stored at $-80^{\circ} \mathrm{C}$ before further processing for ChIP. Cells were pelleted by centrifugation, and suspended in $4 \mathrm{ml}$ of IP buffer (100 mM Tris-HCl pH 8.5, 0.3\% SDS, 1.7\% Triton X-100, $100 \mathrm{~mm} \mathrm{NaCl}$ and $5 \mathrm{~mm}$ EDTA, protease and phosphatase inhibitors). Cells were disrupted by sonication with a Branson 250 sonicator, performing five cycles of $30 \mathrm{~s} 30 \%$ amplitude, yielding genomic DNA fragments with a bulk size of $100-400 \mathrm{bp} .1 \mathrm{ml}$ of diluted lysate was precleared by addition of $25 \mu \mathrm{l}$ of blocked protein A beads $(50 \%$ slurry protein A-Sepharose, 
Amersham; $0.5 \mathrm{mg} / \mathrm{ml}$ fatty acid-free BSA, Sigma; and $0.5 \mathrm{mg} / \mathrm{ml}$ tRNA, Sigma, in TE). Samples were immunoprecipitated overnight at $4{ }^{\circ} \mathrm{C}$ with polyclonal antibodies. Immune complexes were recovered by adding $50 \mu \mathrm{l}$ of blocked protein A beads and incubated for $4 \mathrm{~h}$ at $4{ }^{\circ} \mathrm{C}$. Beads were washed with successive washes in $1 \mathrm{ml}$ of Mixed Micelle Buffer ( $20 \mathrm{~mm}$ Tris$\mathrm{HCl} \mathrm{pH} \mathrm{8,} 150 \mathrm{~mm} \mathrm{NaCl}, 5 \mathrm{~mm}$ EDTA, 5\% (w/v) sucrose, 1\% Triton X-100 and $0.2 \%$ SDS), Buffer 500 (50 mm HEPES pH 7.5, 0.1\% (w/v) deoxycholic acid, $1 \%$ Triton X-100, $500 \mathrm{~mm} \mathrm{NaCl}$ and $1 \mathrm{~mm}$ EDTA), LiCl Detergent Wash Buffer (10 mm Tris- $\mathrm{HCl} \mathrm{pH} \mathrm{8.0,} \mathrm{0.5 \%} \mathrm{(w/v)} \mathrm{deoxycholic} \mathrm{acid,} \mathrm{0.5 \%} \mathrm{NP-40,} 250 \mathrm{~mm}$ $\mathrm{LiCl}$ and $1 \mathrm{~mm}$ EDTA), and TE (pH 7.5). DNA was eluted in TE 2\% SDS and crosslinks reversed by incubation overnight at $65^{\circ} \mathrm{C}$. DNA was then purified by Qiaquick columns (Qiagen, Hilden, DE, USA) and quantified using PicoGreen (Invitrogen, Carlsbad, CA, USA). 2-10 ng ChIP DNA was prepared for HiSeq2000 sequencing with TruSeq ChIP Sample Prep Kit (Illumina, San Diego, CA, USA) following manufacturer instructions.

\section{RNA extraction and analysis}

Total RNA was purified onto RNeasy columns (Qiagen) and treated oncolumn with DNase (Qiagen). Complementary DNA was produced using the reverse transcriptase ImPromll (Promega, Madison, WI, USA). $10 \mathrm{ng}$ of complementary DNA were used for Real-time RT-PCR reactions with FAST SYBR Green Master Mix (Applied Biosystems, Foster City, CA, USA).

RNA-Seq was performed on two biological replicates of four E $\mu-m y c$ $\operatorname{Trp} 53^{K / \Delta}$ lymphomas treated with $100 \mathrm{nM}$ OHT or $1 / 1000$ vol. ethanol for

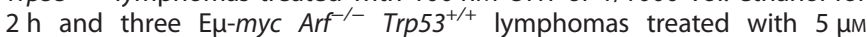
$(-)-$ Nutlin or $1 \mu \mathrm{m}$ doxorubicin for $3 \mathrm{~h}$ and the corresponding controls ( $5 \mu \mathrm{m}(+)$ - Nutlin or $1 / 1000$ vol. $\mathrm{H}_{2} \mathrm{O}$, respectively). Total RNA from $10^{7}$ cells was purified using Trizol (Invitrogen), treated with Turbo DNase (Ambion, Austin, TX, USA) and purified with Agencourt RNA Clean XP (Beckman Coulter, Brea, CA, USA). $5 \mu \mathrm{g}$ of purified RNA were then treated with Ribozero rRNA removal kit (Epicentre, Madison, WI, USA) and ethanol precipitated. RNA quality and removal of rRNA were checked with the Agilent 2100 Bioanalyzer (Agilent Technologies, Santa Clara, CA, USA). Libraries for RNA-Seq were then prepared with the TruSeq RNA Sample Prep Kits v2 (Illumina) following manufacturer instructions starting from the RNA fragmentation step.

The bioinformatic analysis of ChIP-Seq and RNA-Seq data was performed as described below.

\section{Primers}

The following primers were used for mRNA analysis: Cdkn1a for CTGGGAGGGGACAAGAG, Cdkn 1 a rev GCTTGGAGTGATAGAAATCT; Bbc3 for GAGACAAGAAGAGCAGCATCG, Bbc3 rev AAGAGATTGTACATGACCCTCCA; Pmaip 1 for CAGAGCTACCACCTGAGTTCG, Pmaip1 rev TACACTTTGTCTCC GATCTTCCT; Mdm2 for GGAAGATGCGCGGGAAGTA, Mdm2 rev CCGCT CGCCCAGCAG; Bax for AAGCTGAGCGAGTGTCTC, Bax rev CCTTGAGCACC AGTTGC; Trp53 for CGCTGCTCCGATGGTGAT, Trp53 rev TGGCGAAAA GTCTGCCTGTC; Csrnp2 for CTCCTACGACTGCCAGCTTC, Csrnp2 rev GTCAAA GCGGACATTCTTCC; Psrc1 for AGGTGCCCTAGCTCCAGATT, Psrc1 rev CTGGTGGTTGGAAGGTाTGT; Plekho2 for GTाTATGGAAAGACCGCTACTTG, Plekho 2 rev CACCGTCTCTACACATTTCTGC; 4933426M11Rik for TTCAGAAAA CAGTGACATACAAAGC， 4933426M11Rik rev AGCCCTCATGCTTCTITCAA; ErcC5 for AGCACCTGAATGCCCATC, ErCC5 rev GACTCTTTATGAGTTTGG CATCTTG, Hspala for GGCCAGGGCTGGATTACT, Hspala rev GCAACCACCAT GCAAGATTA; Smpd13b for GGATGGGGAGATGGTGTATG, Smpd13b rev GAAGCTGTCGGTATGGTGGT; St6galnac4 for TGGTCTACGGGATGGTCA, St6galnac4 for CTGCTCATGCAAACGGTACAT; Reep6 for GTGCAATGTCATCG GATTT, Reep 6 rev TTGCCCGCGTAGTAGAAAG; PCNA for TTAGATGTGGAGC AACTTGGAAT, PCNA rev CATTCTITGCACAGGATATCACA; Nab1 for GAAA GACCTITGAATCTCCGAAT, Nab1 rev AAGGTGAATGCAGAGTGAGGATA; $\mathrm{Ncl}$ for GTCTGAGGATACCACTGAAG, Ncl rev GCCCAGTCCAAGGTAACT; Smyd2 for AAGGATTGTCAAAATGTGGACGG, Smyd2 rev ATGGAGGAGCATTCCAG CTTG; Tbp for TAATCCCAAGCGATITGCTG, Tbp rev CAGTTGTCCGTGGC TCTCTT.

The following primers were used for ChIP-qPCR analysis: Cdkn1a for TAGCTITCTGGCCTTCAGGA, Cdkn $1 a$ rev GGGGTCTCTGTCTCCATTCA; Bbc3 for CCGTTAGTCTGAGCGTACTCC, Bbc3 rev CGCTTGACACACTGACACACT; Neg. region for AGTGCCCCCTGCTGTCAGT, Neg. region rev CCCTITCC TGGTGCCAAGA; unmarked distal site 1 for GCCTAGCTTGGATCCCCAAT, unmarked distal site 1 rev GCTCCCTGAGAGCACAATGA; unmarked distal site 2 for TGCTAACACAAGGTAGGCGG, unmarked distal site 2 rev GTAACAG TITCCAGCCCCCA; unmarked distal site 3 for AACCTCCCATCAGGACTCTCT, unmarked distal site 3 rev ACTAGTAGCTCGGTGCAACAC; unmarked distal site 4 for TCGTGGAGCACACTTCCAAA, unmarked distal site 4 rev GTTCTCAGCCTCGGGTTCA; enhancer 1 for GGACTCACCATCGAACTCGG, enhancer 1 rev TITGCCCCTCCCCTGTIT; enhancer 2 for AGTGCATACTG AAATGCATACATGA, enhancer 2 rev ACTCTCCACTACTAACCCACTGA; enhancer 3 for AACAGACTGTCAGAAGGGCG, enhancer 3 rev CCTGGGGCAGAG AACATAGC; enhancer 4 for CAGAAAGACTCCTGCGGTGA, enhancer 4 rev TGCTTAGACCTCCTGACTCCT; non-bound site 1 for CTTCGTCACACAGC ACGAGT, non-bound site 1 rev AAACGGCAGTGTTGATTCAG; non-bound site 2 for GGACAGCGAGGACTITGAC, non-bound site 2 rev GCTGTTGTA TAAGCCACCA; non-bound site 3 for GCATTCACTGCACCACAGAG, nonbound site 3 rev CACACGAACAAGGGTGACTG; Csrnp2 for CGACCACGAGGC TTGAAAAC, Csrnp2 rev AACCACGCCAATTCCTCACC; Psrc1 for TGCTGGTGAG AACAGAGAAGC, Psrc1 rev AACATGCCCAGGGACATTCAT; Plekho2 for TGTGGCCTITCTATCTCCCG, Plekho 2 rev TCACTTGCCTCTGGTCCTTG; 4933426M11Rik for TGCTCTGGGAATTCTACACCC, 4933426M11Rik rev CAAAGCCAAGGGCATGTCTC; ErcC5 for GTACATGCCTGGACGTGTGT, Ercc5 rev TAAGCTGGGCACATCGTGAA, Hspala for CCTTGGTATGTATGTGCCCC, Hspala rev CCTTGGCACACAGAGCAATC.

\section{DNasel hypersensitivity}

Genome-wide sequencing of DHS (DNasel Seq) was performed as described. ${ }^{37,38}$ Briefly, apoptotic cells were removed by separation through a Ficoll gradient and live cells were washed with PBS. Pipetting in the following steps was performed with cut tips to avoid DNA breaks due to pipetting force. Cells were resuspended in buffer $\mathrm{A}(15 \mathrm{~mm}$ Tris- $\mathrm{HCl}$ pH 8 , $15 \mathrm{~mm} \mathrm{NaCl}, 60 \mathrm{~mm} \mathrm{KCl}, 1 \mathrm{~mm}$ EDTA pH 8, $0.5 \mathrm{~mm}$ EGTA pH 8, freshly supplemented with $0.5 \mathrm{~mm}$ spermidine and $0.15 \mathrm{~mm}$ spermine). An equal volume of lysis buffer (buffer A with $0.1 \%$ NP-40) was added and the cells were incubated on ice for $10 \mathrm{~min}$. Nuclei were pelleted, washed once with buffer $A$ and then resuspended at a concentration of $50 \times 10^{6}$ nuclei per $\mathrm{ml}$. Then $10^{7}$ nuclei were diluted with an equal volume of $2 \mathrm{X}$ DNasel reaction buffer (Roche). DNasel (Roche, 04716728001) was added at increasing concentrations $(0,100,200,300,400,500 \mathrm{U} / \mathrm{ml})$ and DNA was digested for $10 \mathrm{~min}$ at $37{ }^{\circ} \mathrm{C}$. An equal volume of Stop buffer $(50 \mathrm{~mm}$ Tris- $\mathrm{HCl} \mathrm{pH} \mathrm{8,}$ $100 \mathrm{~mm} \mathrm{NaCl}, 0.1 \%$ SDS, $100 \mathrm{~mm}$ EDTA pH 8, freshly supplemented with $0.5 \mathrm{~mm}$ spermidine, $0.15 \mathrm{~mm}$ spermine and $10 \mu \mathrm{g} / \mathrm{ml}$ of RNase A) was added. Samples were incubated at $55^{\circ} \mathrm{C}$ for $30 \mathrm{~min}$ (220 r.p.m. agitation). Then $0.2 \mu \mathrm{g} / \mathrm{ml}$ of proteinase $\mathrm{K}$ was added and samples were incubated at $55^{\circ} \mathrm{C}$ overnight (220 r.p.m.). DNA was extracted using a standard phenolchloroform extraction protocol, dissolved in $100 \mu$ l of TE $\left(55^{\circ} \mathrm{C}, 2 \mathrm{~h}\right)$. Then $300 \mathrm{ng}$ of DNA of each digested sample was checked on an agarose gel for the appearance of a smear of slightly digested DNA. Small molecular weight DNA was purified using Agencourt AMPure beads (Beckman Coulter). The digested DNA samples $(100 \mu l)$ were supplemented with $50 \mu \mathrm{l}$ of AMPure beads, $150 \mu \mathrm{l}$ of $20 \%$ PEG buffer (20\% PEG8000, $2.5 \mathrm{M}$ $\mathrm{NaCl}$ ) and incubated for $15 \mathrm{~min}$ at room temperature. Beads were separated on a magnet, washed twice with $80 \%$ ethanol and small molecular weight DNA was eluted in $100 \mu \mathrm{l}$ of 5.5\% PEG buffer. The eluted DNA was purified once more ( $20 \mu \mathrm{l}$ of beads; $120 \mu \mathrm{l}$ of $20 \%$ PEG buffer) and after washing eluted in $20 \mu \mathrm{l}$ of $\mathrm{H}_{2} \mathrm{O}$. DNasel performance was checked by $\mathrm{QPCR}$ and samples for sequencing were selected based on the highest signal-to-noise ratio based on selected genomic regions (with 200-300 U/ml of DNasel). Chosen samples were size-selected on an agarose gel, small molecular weight DNA $(<500 \mathrm{bp})$ was eluted from the gel with a Qiagen Gel purification kit according to the manufacturer's instructions. Up to $10 \mathrm{ng}$ DNA was prepared for HiSeq2000 sequencing with TruSeq ChIP Sample Prep Kit (Illumina) following the manufacturer's instructions.

\section{ChIP-Seq and DNasel Seq data analysis}

ChIP-Seq and DNasel Seq NGS reads were aligned to the $\mathrm{mm} 9$ genome through the BWA aligner ${ }^{39}$ using default settings. Peaks were called using the MACS software (v2.0.9), ${ }^{40}$ with the option '- $\operatorname{mfold}=7,30-p$ 0.00001', thus outputting only enriched regions with $P$-value $<10^{-5}$. Normalized read counts within a genomic region were determined as the number of reads per million of library reads (total number of aligned reads in the sequencing library). Peak enrichment was determined as $\log _{2}\left(P{ }^{2} k_{w} / N_{c}-\right.$ input $_{w} / N_{i}$ ), where Peak ${ }_{w}$ is the read count on the enriched region in the ChIP or DNasel sample, input ${ }_{w}$ the read count on the same region in the corresponding input sample, $N_{c}$ is the total number of aligned reads in the ChIP or DNasel sample, and $\mathrm{N}_{\mathrm{i}}$ is the total number of aligned reads in the input sample. 
Promoter peaks were defined as all peaks with at least one base pair overlapping with the interval between $-5 \mathrm{~kb}$ to $+2 \mathrm{~kb}$ from the nearest TSS. The remaining peaks were called distal peaks and were further distinguished between enhancers (H3K4me1-positive regions) and unmarked distal sites (everything else).

\section{RNA-Seq data analysis}

RNA-Seq NGS reads were aligned to the $\mathrm{mm} 9$ mouse reference genome using the TopHat aligner (version 2.0.8) ${ }^{41}$ with default parameters. In case of duplicated reads, only one read was kept. Read counts were associated to each gene (based on UCSC-derived $\mathrm{mm} 9$ GTF gene annotations), using the featureCounts software ${ }^{42}$ (http://bioinf.wehi.edu.au/featureCounts/) setting the options -T 2 - $p$-P. Absolute gene expression was defined determining reads per kilobase per million mapped reads (RPKM) as previously described, ${ }^{43}$ defining total library size as the number of reads mapping to exons only. 14305 genes showed robust expression levels (reads per kilobase per million mapped reads $>1$ in at least one sample) and were considered for further analysis. DEGs were identified using the Bioconductor ${ }^{44}$ package DESeq $2^{45}$ based on read counts, considering genes whose q-value relative to the control is lower than 0.05 .

\section{Other bioinformatic and statistical analyses}

Bioinformatic and statistical analysis were performed using $R$ and Bioconductor packages. ${ }^{44}$ The $z$-scores for the occurrence of p53 motifs in Figures 3a and $d$ were computed as follows: a set of genomic regions equal in number and width to those spanned by the ChIP-Seq peaks was generated over a suitable background (all $(-5 \mathrm{~kb}, 2 \mathrm{~kb})$ regions around the TSS of expressed genes for the promoter peaks, and the whole genome excluding promoters for the distal peaks), and the split and unsplit motifs were counted on these regions. The procedure was repeated 20 times to obtain distributions for split and unsplit motifs (bootstrap). Z-scores were defined as $z=(x-\mu) / \sigma$, where $x$ is the number of motifs counted in the ChIP-Seq peaks, and $\mu$ and $\sigma$ are, respectively, the mean and the standard deviation of the obtained distributions.

\section{Motif search}

The position weight matrix (PWM) from the Jaspar database ${ }^{19}$ described the p53 binding motif, composed by two decameric half sites. In order to account for the possibility of a spacer, an array of 15 PWMs was designed, containing a string of 1-15 uniformly distributed nucleotides between the two halves. The 600 bases flanking the p53 peaks summits were matched to the PWMs with Find Individual Motif Occurrences (FIMO) ${ }^{46}$ with option --thresh 1e-5. When multiple copies of the p53 motif were identified, the peak was associated to the one with the lowest $P$-value, as calculated by find individual motif occurrences.

Gene Set Enrichment Analysis (GSEA) and Gene Ontology analysis The default parameters were used to perform GSEA using the GSEA software. $^{30,31}$ Functional annotation analysis to determine enriched Gene Ontology Biological Processes and KEGG pathways was performed using Database for Annotation, Visualization and Integrated Discovery (DAVID). ${ }^{47,48}$

\section{Data availability}

The NGS datasets used in this work are available on the GEO archive under the accession code GSE80195 (http://www.ncbi.nlm.nih.gov/geo/query/ acc.cgi?acc $=$ GSE80195).

\section{CONFLICT OF INTEREST}

The authors declare no conflict of interest.

\section{ACKNOWLEDGEMENTS}

We thank Gerard Evan for providing us with the $\operatorname{Trp} 53^{K l}$ mice, Theresia Kress and Pranami Bora for discussion and advice, the mouse facility of the IFOM-IEO campus for help with maintenance of the mouse colonies. Grant support: This work was supported by grants from the European Research Council (ERC), the Italian Health Ministry, Fondazione Cariplo and the Italian Association for Cancer Research (AIRC) to Bruno Amati.

\section{REFERENCES}

1 Vousden $\mathrm{KH}$, Prives C. Blinded by the light: the growing complexity of p53. Cell 2009; 137: 413-431.

2 Bieging KT, Mello SS, Attardi LD. Unravelling mechanisms of p53-mediated tumour suppression. Nat Rev Cancer 2014; 14: 359-370.

3 Martins CP, Brown-Swigart L, Evan Gl. Modeling the therapeutic efficacy of p53 restoration in tumors. Cell 2006; 127: 1323-1334.

4 Ventura A, Kirsch DG, McLaughlin ME, Tuveson DA, Grimm J, Lintault L et al. Restoration of p53 function leads to tumour regression in vivo. Nature 2007; 445: 661-665.

5 Xue W, Zender L, Miething C, Dickins RA, Hernando E, Krizhanovsky V et al. Senescence and tumour clearance is triggered by p53 restoration in murine liver carcinomas. Nature 2007; 445: 656-660.

6 Wang Y, Suh YA, Fuller MY, Jackson JG, Xiong S, Terzian T et al. Restoring expression of wild-type p53 suppresses tumor growth but does not cause tumor regression in mice with a p53 missense mutation. J Clin Invest 2011; 121: 893-904.

7 Schmitt CA, Rosenthal CT, Lowe SW. Genetic analysis of chemoresistance in primary murine lymphomas. Nat Med 2000; 6: 1029-1035.

8 Schmitt CA, Lowe SW. BCl-2 mediates chemoresistance in matched pairs of primary E(mu)-myc lymphomas in vivo. Blood Cells Mol Dis 2001; 27: 206-216.

9 Christophorou MA, Martin-Zanca D, Soucek L, Lawlor ER, Brown-Swigart L, Verschuren EW et al. Temporal dissection of $\mathrm{p} 53$ function in vitro and in vivo. Nat Genet 2005; 37: 718-726.

10 Ringshausen I, O'Shea CC, Finch AJ, Swigart LB, Evan GI. Mdm2 is critically and continuously required to suppress lethal p53 activity in vivo. Cancer Cell 2006; 10: 501-514.

11 Schmitt CA, McCurrach ME, de Stanchina E, Wallace-Brodeur RR, Lowe SW. INK4a/ ARF mutations accelerate lymphomagenesis and promote chemoresistance by disabling p53. Genes Dev 1999; 13: 2670-2677.

12 Eischen CM, Weber JD, Roussel MF, Sherr CJ, Cleveland JL. Disruption of the ARF-Mdm2-p53 tumor suppressor pathway in Myc-induced lymphomagenesis. Genes Dev 1999; 13: 2658-2669.

13 Fritsche M, Haessler C, Brandner G. Induction of nuclear accumulation of the tumor-suppressor protein p53 by DNA-damaging agents. Oncogene 1993; 8: 307-318.

14 Vassilev L, Vu B, Graves B, Carvajal D, Podlaski F, Filipovic Z et al. In vivo activation of the p53 pathway by small-molecule antagonists of Mdm2. Science 2004; 303: 844-848.

15 Campaner S, Amati B. Two sides of the Myc-induced DNA damage response: from tumor suppression to tumor maintenance. Cell Div 2012; 7: 6.

16 Macias $\mathrm{E}$, Jin $\mathrm{A}$, Deisenroth $\mathrm{C}$, Bhat $\mathrm{K}$, Mao $\mathrm{H}$, Lindstrom MS et al. An ARF-independent C-MYC-activated tumor suppression pathway mediated by ribosomal protein-Mdm2 interaction. Cancer Cell 2010; 18: 231-243.

17 Menendez D, Nguyen TA, Freudenberg JM, Mathew VJ, Anderson CW, Jothi R et al. Diverse stresses dramatically alter genome-wide p53 binding and transactivation landscape in human cancer cells. Nucleic Acids Res 2013; 41: 7286-7301.

18 Tonelli C, Morelli MJ, Bianchi S, Rotta L, Capra T, Sabò A et al. Genome-wide analysis of p53 transcriptional programs in B cells upon exposure to genotoxic stress in vivo. Oncotarget 2015; 6: 24611-24626.

19 Mathelier A, Zhao X, Zhang AW, Parcy F, Worsley-Hunt R, Arenillas DJ et al. JASPAR 2014: an extensively expanded and updated open-access database of transcription factor binding profiles. Nucleic Acids Res 2014; 42: D142-D147.

20 Riley T, Sontag E, Chen P, Levine A. Transcriptional control of human p53regulated genes. Nat Rev Mol Cell Biol 2008; 9: 402-412.

21 Chang GS, Chen XA, Park B, Rhee HS, Li P, Han KH et al. A comprehensive and high-resolution genome-wide response of p53 to stress. Cell Rep 2014; 8: 514-527.

22 Sabò A, Kress TR, Pelizzola M, de Pretis S, Gorski MM, Tesi A et al. Selective transcriptional regulation by Myc in cellular growth control and lymphomagenesis. Nature 2014; 511: 488-492.

23 Sammons MA, Zhu J, Drake AM, Berger SL. TP53 engagement with the genome occurs in distinct local chromatin environments via pioneer factor activity. Genome Res 2015; 25: 179-188.

24 Su D, Wang X, Campbell MR, Song L, Safi A, Crawford GE et al. Interactions of chromatin context, binding site sequence content, and sequence evolution in stress-induced p53 occupancy and transactivation. PLoS Genet 2015; 11: e1004885

25 Li M, He Y, Dubois W, Wu X, Shi J, Huang J. Distinct regulatory mechanisms and functions for p53-activated and p53-repressed DNA damage response genes in embryonic stem cells. Mol Cell 2012; 46: 30-42.

26 Kenzelmann Broz D, Spano Mello S, Bieging KT, Jiang D, Dusek RL, Brady CA et al. Global genomic profiling reveals an extensive p53-regulated autophagy program contributing to key p53 responses. Genes Dev 2013; 27: 1016-1031.

27 Smeenk L, van Heeringen SJ, Koeppel M, Gilbert B, Janssen-Megens $E$, Stunnenberg HG et al. Role of p53 serine 46 in p53 target gene regulation. PloS One 2011; 6: e17574. 
28 Nikulenkov F, Spinnler C, Li H, Tonelli C, Shi Y, Turunen M et al. Insights into p53 transcriptional function via genome-wide chromatin occupancy and gene expression analysis. Cell Death Differ 2012; 19: 1992-2002.

29 Schlereth K, Heyl C, Krampitz AM, Mernberger M, Finkernagel F, Scharfe M et al. Characterization of the $\mathrm{p} 53$ cistrome--DNA binding cooperativity dissects p53's tumor suppressor functions. PLoS Genet 2013; 9: e1003726.

30 Subramanian A, Tamayo P, Mootha VK, Mukherjee S, Ebert BL, Gillette MA et al. Gene set enrichment analysis: a knowledge-based approach for interpreting genome-wide expression profiles. Proc Natl Acad Sci USA 2005; 102: 15545-15550.

31 Mootha VK, Lindgren CM, Eriksson KF, Subramanian A, Sihag S, Lehar J et al. PGC-1alpha-responsive genes involved in oxidative phosphorylation are coordinately downregulated in human diabetes. Nat Genet 2003; 34: 267-273.

32 Renault VM, Thekkat PU, Hoang KL, White JL, Brady CA, Kenzelmann Broz D et al. The pro-longevity gene $\mathrm{FoxO} 3$ is a direct target of the p53 tumor suppressor. Oncogene 2011; 30: 3207-3221.

33 Wei CL, Wu Q, Vega VB, Chiu KP, Ng P, Zhang T et al. A global map of p53 transcription-factor binding sites in the human genome. Cell 2006; 124: 207-219.

34 Okamura S, Arakawa H, Tanaka T, Nakanishi H, Ng CC, Taya Y et al. p53DINP1, a p53-inducible gene, regulates p53-dependent apoptosis. Mol Cell 2001; 8: 85-94.

35 Adams JM, Harris AW, Pinkert CA, Corcoran LM, Alexander WS, Cory S et al. The c-myc oncogene driven by immunoglobulin enhancers induces lymphoid malignancy in transgenic mice. Nature 1985; 318: 533-538.

36 Kamijo T, Zindy F, Roussel MF, Quelle DE, Downing JR, Ashmun RA et al. Tumor suppression at the mouse INK4a locus mediated by the alternative reading frame product p19ARF. Cell 1997; 91: 649-659.

$37 \mathrm{He} \mathrm{HH}$, Meyer CA, Chen MW, Jordan VC, Brown M, Liu XS. Differential DNase hypersensitivity reveals factor-dependent chromatin dynamics. Genome Res 2012; 22: 1015-1025.

38 Sabo PJ, Kuehn MS, Thurman R, Johnson BE, Johnson EM, Cao H et al. Genomescale mapping of DNase I sensitivity in vivo using tiling DNA microarrays. Nat Methods 2006; 3: 511-518.

$39 \mathrm{Li} \mathrm{H}$, Durbin R. Fast and accurate short read alignment with Burrows-Wheeler transform. Bioinformatics 2009; 25: 1754-1760.
40 Zhang Y, Liu T, Meyer CA, Eeckhoute J, Johnson DS, Bernstein BE et al. Model-based analysis of ChIP-Seq (MACS). Genome Biol 2008; 9: R137.

41 Kim D, Pertea G, Trapnell C, Pimentel H, Kelley R, Salzberg SL. TopHat2: accurate alignment of transcriptomes in the presence of insertions, deletions and gene fusions. Genome Biol 2013; 14: R36.

42 Liao Y, Smyth GK, Shi W. featureCounts: an efficient general purpose program for assigning sequence reads to genomic features. Bioinformatics 2014; 30: 923-930.

43 Mortazavi A, Williams BA, McCue K, Schaeffer L, Wold B. Mapping and quantifying mammalian transcriptomes by RNA-Seq. Nat Methods 2008; 5: 621-628.

44 Gentleman RC, Carey VJ, Bates DM, Bolstad B, Dettling M, Dudoit S et al. Bioconductor: open software development for computational biology and bioinformatics. Genome Biol 2004; 5: R80.

45 Love Ml, Huber W, Anders S. Moderated estimation of fold change and dispersion for RNA-seq data with DESeq2. Genome Biol 2014; 15: 550.

46 Grant CE, Bailey TL, Noble WS. FIMO: scanning for occurrences of a given motif. Bioinformatics 2011; 27: 1017-1018.

47 Huang, da W, Sherman BT, Lempicki RA. Bioinformatics enrichment tools: paths toward the comprehensive functional analysis of large gene lists. Nucleic Acids Res 2009; 37: 1-13.

48 Huang, da W, Sherman BT, Lempicki RA. Systematic and integrative analysis of large gene lists using DAVID bioinformatics resources. Nat Protoc 2009; 4: 44-57.

(c) (i) $\Theta$ This work is licensed under a Creative Commons AttributionBY NC ND NonCommercial-NoDerivs 4.0 International License. The images or other third party material in this article are included in the article's Creative Commons license, unless indicated otherwise in the credit line; if the material is not included under the Creative Commons license, users will need to obtain permission from the license holder to reproduce the material. To view a copy of this license, visit http:// creativecommons.org/licenses/by-nc-nd/4.0/

(c) The Author(s) 2017

Supplementary Information accompanies this paper on the Oncogene website (http://www.nature.com/onc) 